OPEN ACCESS

Edited by: Lucian Constantin Staicu, University of Warsaw, Poland

Reviewed by:

Ruiyong Zhang,

Chinese Academy of Sciences (CAS),

China

Eva Pakostova

Coventry University, United Kingdom

*Correspondence:

Julie Cosmidis

julie.cosmidis@earth.ox.ac.uk

Specialty section:

This article was submitted to Microbiological Chemistry and Geomicrobiology,

a section of the journal

Frontiers in Microbiology

Received: 03 June 2021 Accepted: 15 July 2021 Published: 06 August 2021

Citation:

Cron B, Macalady JL and Cosmidis J (2021) Organic Stabilization of Extracellular Elemental Sulfur in a Sulfurovum-Rich Biofilm: A

New Role for Extracellular

Polymeric Substances?

Front. Microbiol. 12:720101.

doi: 10.3389/fmicb.2021.720101

\section{Organic Stabilization of Extracellular Elemental Sulfur in a Sulfurovum- Rich Biofilm: A New Role for Extracellular Polymeric Substances?}

\author{
Brandi Cron ${ }^{1,2}$, Jennifer L. Macalady ${ }^{2}$ and Julie Cosmidis ${ }^{2,3 *}$ \\ ${ }^{1}$ Salish Sea Research Center, Northwest Indian College, Bellingham, WA, United States, ${ }^{2}$ Department of Geosciences, The \\ Pennsylvania State University, University Park, PA, United States, ${ }^{3}$ Department of Earth Sciences, University of Oxford, \\ Oxford, United Kingdom
}

This work shines light on the role of extracellular polymeric substance (EPS) in the formation and preservation of elemental sulfur biominerals produced by sulfur-oxidizing bacteria. We characterized elemental sulfur particles produced within a Sulfurovum-rich biofilm in the Frasassi Cave System (Italy). The particles adopt spherical and bipyramidal morphologies, and display both stable $\left(\alpha-S_{8}\right)$ and metastable $\left(\beta-S_{8}\right)$ crystal structures. Elemental sulfur is embedded within a dense matrix of EPS, and the particles are surrounded by organic envelopes rich in amide and carboxylic groups. Organic encapsulation and the presence of metastable crystal structures are consistent with elemental sulfur organomineralization, i.e., the formation and stabilization of elemental sulfur in the presence of organics, a mechanism that has previously been observed in laboratory studies. This research provides new evidence for the important role of microbial EPS in mineral formation in the environment. We hypothesize that the extracellular organics are used by sulfur-oxidizing bacteria for the stabilization of elemental sulfur minerals outside of the cell wall as a store of chemical energy. The stabilization of energy sources (in the form of a solid electron acceptor) in biofilms is a potential new role for microbial EPS that requires further investigation.

Keywords: sulfur, biomineralization, organomineralization, extracellular polymeric substances, biofilms, Raman, STXM

\section{INTRODUCTION}

Elemental sulfur $[S(0)]$ is an intermediate of the biogeochemical sulfur cycle found in many natural environments, such as marine sediments, marine and lacustrine water columns, cold or hot springs, hydrothermal environments, salt marshes, and caves (Zerkle et al., 2010; Findlay et al., 2014; Hamilton et al., 2015; Lau et al., 2017; Jørgensen et al., 2019). S(0) is formed by chemical or biological oxidation of more reduced sulfur species, although in low-temperature environments, biological S-oxidation rates are typically more than three orders of magnitude faster than abiotic rates (Luther et al., 2011). A wide diversity of microorganisms can oxidize sulfide, polysulfides, or thiosulfate and precipitate $S(0)$ through both phototrophic and chemotrophic pathways (Kleinjan et al., 2003; Dahl and Prange, 2006). In turn, microbially 
formed $S(0)$ can be used as a source of energy for a wide diversity of S-oxidizers, S-reducers, and microorganisms that perform $S(0)$ disproportionation (Warthmann et al., 1992; Dahl, 2020a). Elemental sulfur thus occupies a central and ecologically important role in the biogeochemical sulfur cycle.

Biogenic $S(0)$ is deposited either intracellularly or extracellularly (Kleinjan et al., 2003; Dahl and Prange, 2006; Maki, 2013). Most studies on microbial S(0) biomineralization so far have focused on microorganisms forming intracellular $\mathrm{S}(0)$ globules, for instance Allochromatium vinosum, Acidithiobacillus ferrooxidans, Thiothrix spp., or large colorless SOB, such as Thiomargarita namibiensis, Thioploca spp., or Beggiatoa spp. (Brune, 1995; Gray and Head, 1999; Pasteris et al., 2001; Prange et al., 2002; Maki, 2013; Nims et al., 2019; Dahl, 2020b). Many SOB can form S(0) extracellularly, such as green sulfur bacteria (Chlorobiaceae; Gregersen et al., 2011; Marnocha et al., 2016), purple sulfur bacteria of the Ectothiorhodospiraceae family (Then and Trüper, 1983), some purple non-sulfur bacteria (Hansen and van Gemerden, 1972), some lithotrophic sulfur bacteria (Cron et al., 2019), and cyanobacteria (Oren and Shilo, 1979). More work is needed to decipher the formation mechanisms of extracellular $S(0)$ and to characterize its properties.

In sulfide-rich solutions, $S(0)$ is thermodynamically stable only under a very restricted range of natural Eh-pH conditions (e.g., Eh -0.05 to 0.15 and $\mathrm{pH}<5$ at $25^{\circ} \mathrm{C}$ and 1 bar; see Figure 7 in Rickard and Luther, 2007). It is thus not clear how microbial sulfur, particularly when it is extracellular, persists in most circumneutral aqueous environments. Cosmidis et al. (2019) recently showed that interactions with organics are important for the abiotic formation of $S(0)$ minerals, a process termed $S(0)$ organomineralization. Organomineralized sulfur can be found in several metastable crystal structures, including the monoclinic allotropes $\beta-S_{8}$ and $\gamma-S_{8}$, which are thought to be stabilized by close association with organics. Organic-mineral interactions may also be important in extracellular $S(0)$ formation by bacteria. Indeed, organics produced by the chemolithoautotrophic SOB Sulfuricurvun (S.) kujiense (Campylobacterota) are needed for extracellular $\mathrm{S}(0)$ formation by this organism. The $\mathrm{S}(0)$ globules of $S$. kujiense are composed of $\beta-S_{8}$ and $\gamma-S_{8}$ and are coated by organic envelopes that allow them to precipitate under conditions outside of their theoretical thermodynamic stability domain (Cron et al., 2019). Other SOB, such as Thiobacillus sp. W5 (Kleinjan et al., 2005) and Chlorobaculum (C.) tepidum (Hanson et al., 2016; Marnocha et al., 2019), also produces extracellular $S(0)$ globules with organic envelopes, suggesting that organics play a previously overlooked role in microbial $S(0)$ formation and stabilization in nature.

Previous studies describing the importance of organics in $S(0)$ mineralization were based on laboratory experiments, whereas observations from natural environments are still lacking. Elemental sulfur particles with metastable structures and intimate associations with organics were described in a sulfur-rich glacial site in the Arctic, but it could not be determined whether microbial mediation was involved in their formation (Lau et al., 2017). In the present study, we characterized extracellular $S(0)$ particles formed within microbial biofilms in a subsurface environment dominated by sulfur-cycling bacteria. The Grotto Grande del Vento-Grotta del Fiume (Frasassi) cave system is actively forming in Jurassic limestone in the Apennine Mountains of the Marches Region, Central Italy (D’Angeli et al., 2019). The $S(0)$ minerals described here are found within microbial biofilms in a microaerophilic sulfide-rich stream, Pozzo di Cristalli. Previous full-cycle rRNA and metagenomic approaches identified Campylobacterota most closely affiliated with Sulfurovum species as the most abundant organisms in streamer biofilms at this location (Jones et al., 2008; Macalady et al., 2008; Hamilton et al., 2015). Sulfurovum oxidize sulfide and thiosulfate to sulfate and extracellular $\mathrm{S}(0)$ globules, which can make up more than $60 \%$ by weight of their mats. These primary producers serve as the principal source of organic carbon to the subsurface stream ecosystem (Hamilton et al., 2015). The biofilms are attached to rocks in the stream bed where they intersect the water surface. In this environment, sulfidic water turbulently mixes with oxygen in the cave air, providing chemical energy for growth (Macalady et al., 2008).

We characterized the morphology and crystal structure of $S(0)$ particles formed by microbial S-oxidation in these natural Sulfurovum-dominated biofilms using scanning electron microscopy (SEM), X-ray diffraction (XRD), and ultra-lowfrequency Raman spectromicroscopy. Organics closely associated with the $S(0)$ minerals were also characterized using Fourier-transform infrared (FTIR) spectroscopy and scanning transmission X-ray microscopy (STXM). Our results provide important clues about how organic compounds (e.g., carboxylic acids, amides, aromatics, and aliphatic compounds) excreted by cells are used to encapsulate and stabilize extracellular S(0) within EPS matrices. We discuss the ecological implications of this new role of EPS in sulfur-based microbial ecosystems.

\section{MATERIALS AND METHODS}

\section{Biofilm Sample Collection}

Pozzo di Cristalli is a cave stream that periodically hosts blooms of streamer biofilms primarily composed of Campylobacterota in the genus Sulfurovum (Jones et al., 2008; Macalady et al., 2008; Hamilton et al., 2015). The biofilms thrive in turbulent stream riffles near the air-water interface. Sulfide concentration was $20.5 \mu \mathrm{M}$ at the time of sampling in September 2016. Streamer sample PC1647 was harvested from customized floating twine supports. In September 2017, a Sulfurovum-dominated biofilm (streamer sample PC1718) was collected from a limestone cobble at the same location (Figure 1). Biofilm samples were divided into sterile Falcon tubes and cryotubes. Samples in Falcon tubes were preserved with glutaraldehyde and stored at $-20^{\circ} \mathrm{C}$. Cryotube samples were stored at $-80^{\circ} \mathrm{C}$.

\section{X-Ray Diffraction}

For XRD, approximatively $1 \mathrm{ml}$ of biofilm sample PC1718 (i.e., the condensed content of a microcentrifuge tube) was rinsed three times with deionized water and deposited on a 


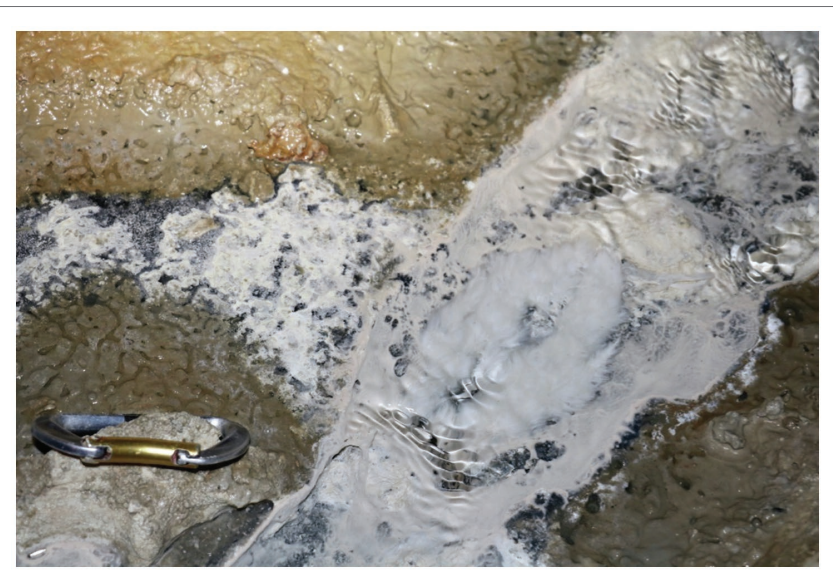

FIGURE 1 | Biofilm collection site in September 2017 with billowing white Sulfurovum-rich streamer biofilm on the surface of the stream at center right. The Sulfurovum-dominated biofilm is surrounded by a weakly pigmented Beggiatoa biofilm growing on the black sediment surface.

single crystal miscut Si holder. Samples were analyzed using a PANalytical Empyrean diffractometer paired with a PIXcel3D detector, and $\mathrm{Cu} \mathrm{K} \alpha(\lambda=1.5406 \AA)$ incident $\mathrm{X}$-ray radiation. Scans were conducted over a $2 \theta$ range of $5-70^{\circ}$, and analyses used a step size of $0.025^{\circ}$, a time of $96.4 \mathrm{~s}$ per step, and a current density of $40 \mathrm{~mA}$. XRD data were analyzed using MDI JADE software. Mineral identification was performed by comparison with reference XRD patterns from the International Centre for Diffraction Data (ICDD) database.

\section{Raman Spectromicroscopy}

For Raman, $5 \mathrm{ml}$ of frozen unpreserved biofilm (sample PC1718) was rinsed three times with deionized water to remove salts. Samples were either deposited and dried on a microscope slide or kept wet between a microscope slide and cover slip. Raman spectra were collected using a Horiba LabRam HR Evolution Vis-NIR optimized \& AIST-NT Scanning Probe, and a Si-based CCD detector $(1,024 \times 256$ pixels $)$. Raman signals were measured in the low-frequency range using BragGrate notch filters (Nims et al., 2019). The spectrometer was calibrated using the $520 \mathrm{~cm}^{-1}$ Raman peak of Si prior to analysis. Spectral data were corrected for instrumental artifacts and baselinesubtracted using a polynomial fitting algorithm in LabSpec 6 (Horiba Scientific). The sample spectra were compared with reference Raman spectra for different allotropes of $S(0)$ (Nims et al., 2019).

\section{Scanning Electron Microscopy}

For SEM, biofilm samples were rinsed with deionized water and deposited on polycarbonate filters (GTTP Isopore membrane filters, Merck Millipore, pore size $0.2 \mu \mathrm{m}$ ) or on glass slides (for correlative Raman analyses, see below). The samples were allowed to dry at ambient temperature and coated with iridium or gold prior to analysis. For sample PC1718, SEM analyses were conducted on a Field Emission Nova NanoSEM 630 at the Materials Characterization
Laboratory at The Pennsylvania State University. Images were acquired with the microscope operating at $3-7 \mathrm{kV}$ and a working distance (WD) of $\sim 3-5 \mathrm{~mm}$. Energy-dispersive X-ray spectroscopy (EDXS) analyses were performed at $12 \mathrm{kV}$ and WD $\sim \mathrm{mm}$. For sample PC1647, SEM analyses were conducted on a JSM-7401F field emission scanning electron microscope (FESEM) at the Nanoscale Fabrication Laboratory at the University of Colorado at Boulder. Images were acquired in the secondary electron mode with the microscope operating at $5 \mathrm{kV}$ and a WD of $6 \mathrm{~mm}$, and in the backscattered electron mode at $15 \mathrm{kV}$ and WD $8 \mathrm{~mm}$. EDXS analyses were performed at $20 \mathrm{kV}$ and WD $8 \mathrm{~mm}$.

To correlate Raman data with morphological characterization of the S(0) particles, we designed a correlative Raman-SEM protocol. A frozen unpreserved biofilm sample (PC1718) was rinsed three times with deionized water to remove salts and deposited on a microscope glass slide. The sample was air-dried, and the $\mathrm{S}(0)$ particles were first analyzed using Raman. The microscope slide was then coated with iridium and analyzed by SEM on a Field Emission Nova NanoSEM 630 (see details on SEM operations below). Raman-based crystallographic characterization of the $S(0)$ minerals was performed before SEM imaging in order to prevent potential structural alteration in the dry, low-vacuum environment of the SEM chamber.

\section{Fourier-Transform Infrared Spectroscopy}

For FTIR spectroscopy, $1 \mathrm{ml}$ of unpreserved biofilm (sample PC1718) was rinsed three times with deionized water and dried in a vacuum oven at $60^{\circ} \mathrm{C}$ overnight. Then, $6 \mathrm{mg}$ of dried sample and $100 \mathrm{mg} \mathrm{KBr}$ were ground and pelleted. FTIR measurements were conducted on a vertex 70 spectrometer (Bruker Optics) equipped with a deuterated triglycerine sulfate (DTGS) detector and a high-intensity water-cooled Globar source. Spectra were collected at $5 \mathrm{~cm}^{-1}$ resolution $(2.5 \mathrm{~mm}$ aperture) as an average of 100 scans using MVP PRO software (Harrick Scientific). The instrument was purged for $30 \mathrm{~min}$ before the first measurement to ensure baseline stability. The FTIR analyses were performed on three separate occasions on distinct aliquots of the biofilm, and the obtained spectra were similar between analyses. The spectra were baseline corrected using the "Rubber Band" algorithm within the OPUS 2.2 software. The experimental spectra were plotted with reference spectra for calcite and quartz (RRUFF database; Lafuente et al., 2015).

\section{Scanning Transmission X-Ray Microscopy and $C$ K-Edge and S L-Edge X-Ray Absorption Spectroscopy}

For STXM, $1 \mathrm{ml}$ of unpreserved biofilm (samples PC1647 and PC1718) was rinsed three times with deionized water. A small drop of the suspension $(\sim 3 \mu \mathrm{l})$ was deposited on a Formvarcoated 200 mesh Cu TEM grid (Ted Pella) and allowed to air-dry at ambient temperature. STXM analyses were performed on beamline 10ID-1 (SM) of the Canadian Light Source (Saskatoon, Canada), and beamline 11.0.2. of the Advanced 
Light Source (ALS, Berkeley, CA). The X-ray beam was focused on the samples using a Fresnel zone plate objective and an order-sorting aperture yielding a focused X-ray beam spot of $\sim 30 \mathrm{~nm}$ on the samples. After sample insertion in the STXM microscope, the chamber was evacuated to 100 mTorr and back-filled with $\mathrm{He}$ at $\sim 1$ atm pressure. Energy calibration was achieved using the well-resolved $3 p$ Rydberg peak of gaseous $\mathrm{CO}_{2}$ at $294.96 \mathrm{eV}$. Images, maps, and image stacks were acquired in the 260-340 eV (C K-edge) and 155-190 eV (S L-edge) energy ranges.

Scanning transmission X-ray microscopy data were processed using aXis2000 software. Maps of organic C were obtained by subtracting images obtained at $280 \mathrm{eV}$ (i.e., below the $\mathrm{C}$ K-edge) and converted into optical density (OD) from OD-converted images at $288.2 \mathrm{eV}\left(1 \mathrm{~s} \rightarrow \pi^{\star}\right.$ electronic transitions in amide groups). Maps of $\mathrm{S}$ were obtained by subtracting OD-converted images obtained at $160 \mathrm{eV}$ (i.e., below the S L-edge) from OD-converted images at $163.5 \mathrm{eV}$ (energy of the $\mathrm{S}_{3}$-edge). X-ray absorption near-edge structure (XANES) spectra were extracted from image stacks as explained in Cosmidis and Benzerara (2014). Different types of objects (e.g., cells, EPS, and sulfur particles) were visually identified in STXM images and maps. Regions of interest were manually selected, and their distinctive XANES spectra were extracted from the stacks and plotted. A linear background correction was applied to the XANES spectra at the C K-edge and the $\mathrm{S}$ L-edge, in the 260-280 eV region and 155-160 eV region, respectively, to eliminate the contributions of lower energy absorption edges.

\section{RESULTS}

\section{Morphology of Elemental Sulfur Particles in Sulfurovum-Dominated Biofilms}

Scanning electron microscopy imaging combined with EDXS analyses of the Sulfurovum-dominated biofilms revealed abundant sulfur-rich particles within a dense matrix of EPS (Figure 2; Supplementary Figures S1, S2). The particles appear as spheroids and bipyramidal crystals, which are sometimes fused into elongated chains (Figure 2A; Supplementary Figure S1). The particles may also adopt more irregular shapes. The EPS appears either film-like (Figure 2C) or as a web made from a network of thin threads (Figure 2F). Figure 3 shows the size distribution of S(0) spheroids in two biofilm samples [PC1647 $(n=1,354)$ and PC1718 $(n=256)]$. The diameters of the spheroids range from 0.1 to $3.5 \mu \mathrm{m}$, with an average diameter of $1.31 \mu \mathrm{m}$ for PC1347 and $1.03 \mu \mathrm{m}$ for PC1718. Bipyramids are not abundant enough to plot their size distribution, but range between 1.9 and $4.8 \mu \mathrm{m}$ in length.

\section{Crystal Structure of Elemental Sulfur X-Ray Diffraction}

$\mathrm{X}$-ray diffraction analyses performed on sample PC1718 indicate that the biofilm contains $S(0)$ present as orthorhombic $\alpha-S_{8}$ and monoclinic $\beta-S_{8}$ (Figure 4), as determined by comparison with S(0) XRD patterns from the ICDD database. Calcite and quartz minerals were also detected.
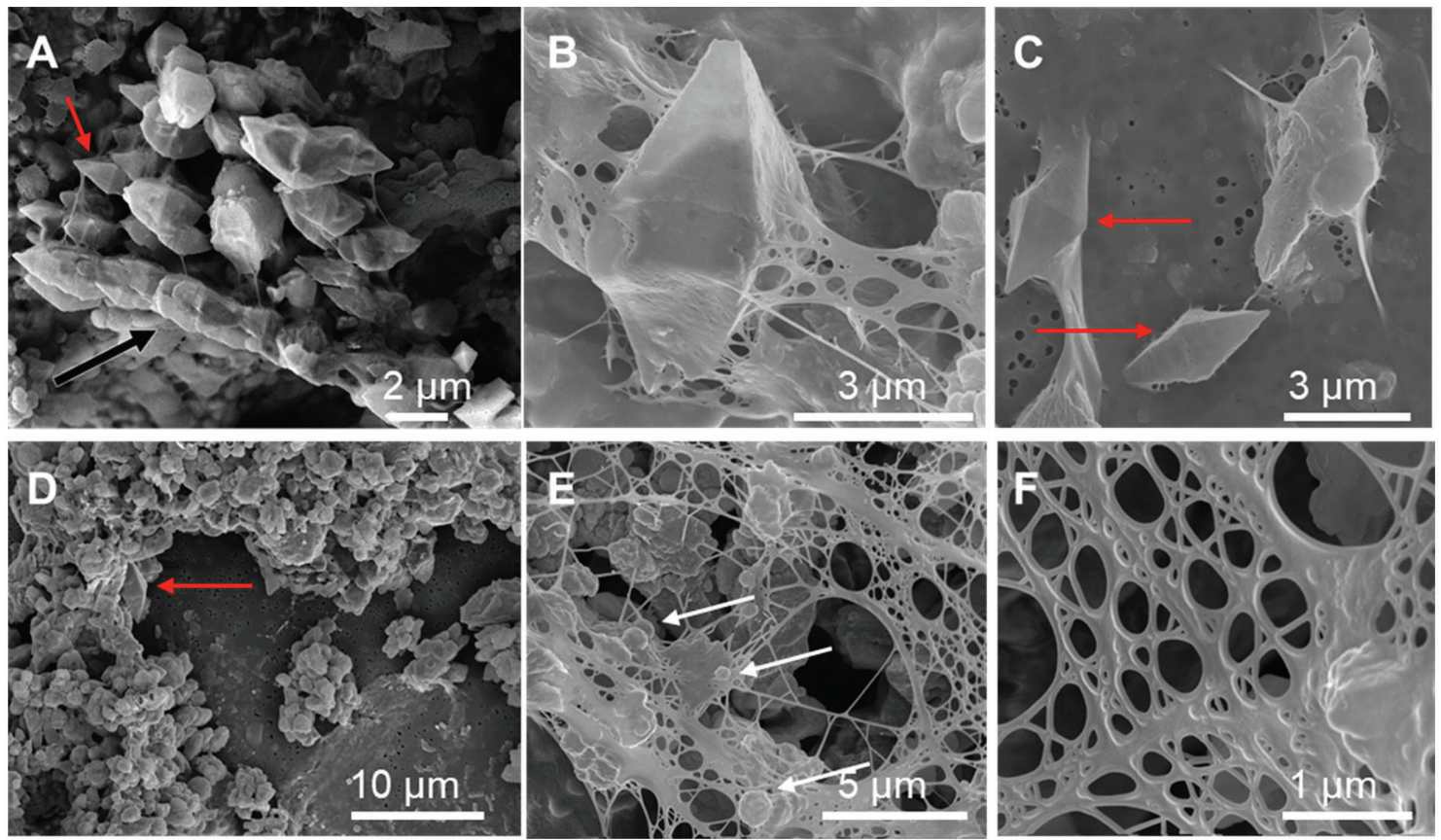

FIGURE 2 | Scanning electron microscopy images of sulfur particles associated with EPS in Sulfurovum-dominated streamer biofilms. Samples include (A) PC1647 and (B-F) PC1718. Red arrows point to bipyramidal S(0) crystals and white arrows point to S(0) spheroids. (A) shows an example of a chain formed by fused bipyramidal $\mathrm{S}(0)$ crystals (black arrow). 


\section{Correlative Scanning Electron Microscopy and Raman Spectromicroscopy}

In order to determine the relationship between $S(0)$ crystal structure and particle morphology, Raman spectroscopy correlated with SEM imaging was performed on sample PC1718. Crystal structure identification was performed by comparison with low-frequency Raman spectra for different reference $S(0)$ allotropes (Nims et al., 2019). The $\alpha-S_{8}$ allotrope can be identified using the low-frequency range Raman vibration modes at $28 \mathrm{~cm}^{-1}, 44 \mathrm{~cm}^{-1}, 51 \mathrm{~cm}^{-1}, 63 \mathrm{~cm}^{-1}$, and a doublet at $82 \mathrm{~cm}^{-1}$ and $88 \mathrm{~cm}^{-1}$ (Figure 5C). The $\beta-S_{8}$ allotrope displays distinctive vibrations in the low-frequency range with a peak positioned at $82 \mathrm{~cm}^{-1}$, a doublet at $33 \mathrm{~cm}^{-1}$ and $42 \mathrm{~cm}^{-1}$, and a shoulder at $60 \mathrm{~cm}^{-1}$. Spheroids were found to be composed of either $\alpha-S_{8}$ or $\beta-S_{8}$ (Figures $5 \mathbf{A}, \mathbf{B}, \mathbf{D}$ ). These two allotropes were sometimes found in close association with each other (Figure $5 \mathbf{E}$ ). We attempted to determine the crystal structure of $\mathrm{S}(0)$ bipyramids, but they could not be found in the sample during Raman analyses due to their relative rarity.

\section{Association of Elemental Sulfur With EPS and Encapsulating Organics}

\section{Fourier-Transform Infrared Spectroscopy}

Fourier-transform infrared (FTIR) spectroscopy was performed on the unpreserved PC1718 sample (Figure 6). Reference spectra for calcite and quartz were used to assist in the interpretation of the FTIR data, since these minerals were identified in the sample based on XRD (Figure 4). The sample spectrum displays a broad band centered around $3,400-3,430 \mathrm{~cm}^{-1}$ corresponding to $\mathrm{O}-\mathrm{H}$ stretching frequencies (Supplementary Figure S3). The broad peak around $1,750 \mathrm{~cm}^{-1}$ corresponds to stretching of $\mathrm{COOH}$ or $\mathrm{COOR}$ in carboxylic acids and aromatic esters (Artz et al., 2008). Signal in this region is also attributed to $\mathrm{C}=\mathrm{O}$ stretching in esters and fatty acids (Schmitt and Flemming, 1998). Peak signal around $1,650-1,600 \mathrm{~cm}^{-1}$ is attributed to stretching of aromatic $\mathrm{C}=\mathrm{C}$ or asymmetric $\mathrm{C}-\mathrm{O}$ stretching in $\mathrm{COO}^{-}$ (carboxylates; The presence of carboxylic acids in our sample is further supported by the presence of a peak at $1,426 \mathrm{~cm}^{-1}$ originating from symmetric $\mathrm{C}=\mathrm{O}$ stretching and $\mathrm{OH}$ deformation in $\mathrm{COOH}$ from carboxylates or carboxylic acid structures (Thomas, 1972). The band at $1,056 \mathrm{~cm}^{-1}$ is attributed to phosphates in nucleic acids (Orhan Yanıkan et al., 2020) and/or to quartz. A sharp peak at $879 \mathrm{~cm}^{-1}$ is present, commonly interpreted as out of phase ring stretching (ring "breathing") of aromatics (Artz et al., 2008). Peaks at 470 and $424 \mathrm{~cm}^{-1}$ are attributed to S-S stretching in $S_{8}$ (Meyer, 1976; Steudel and Eckert, 2003). The presence of quartz is confirmed by peaks at 692,776 , and $795 \mathrm{~cm}^{-1}$ and a shoulder at $1,160 \mathrm{~cm}^{-1}$. The peak at $516 \mathrm{~cm}^{-1}$ is representative of calcite. Quartz peaks may overlap with the molecular vibrations of polysaccharides in the 1,200$900 \mathrm{~cm}^{-1}$ region, which are typically observed in FTIR spectra of EPS (Naumann et al., 1991).

Fourier-transform infrared analysis thus confirmed the presence of quartz, calcite, and $S(0)$ minerals in the biofilm, while signal from the organic material shows a composition dominated by carboxylic acids, carboxylates, and aromatic structures.

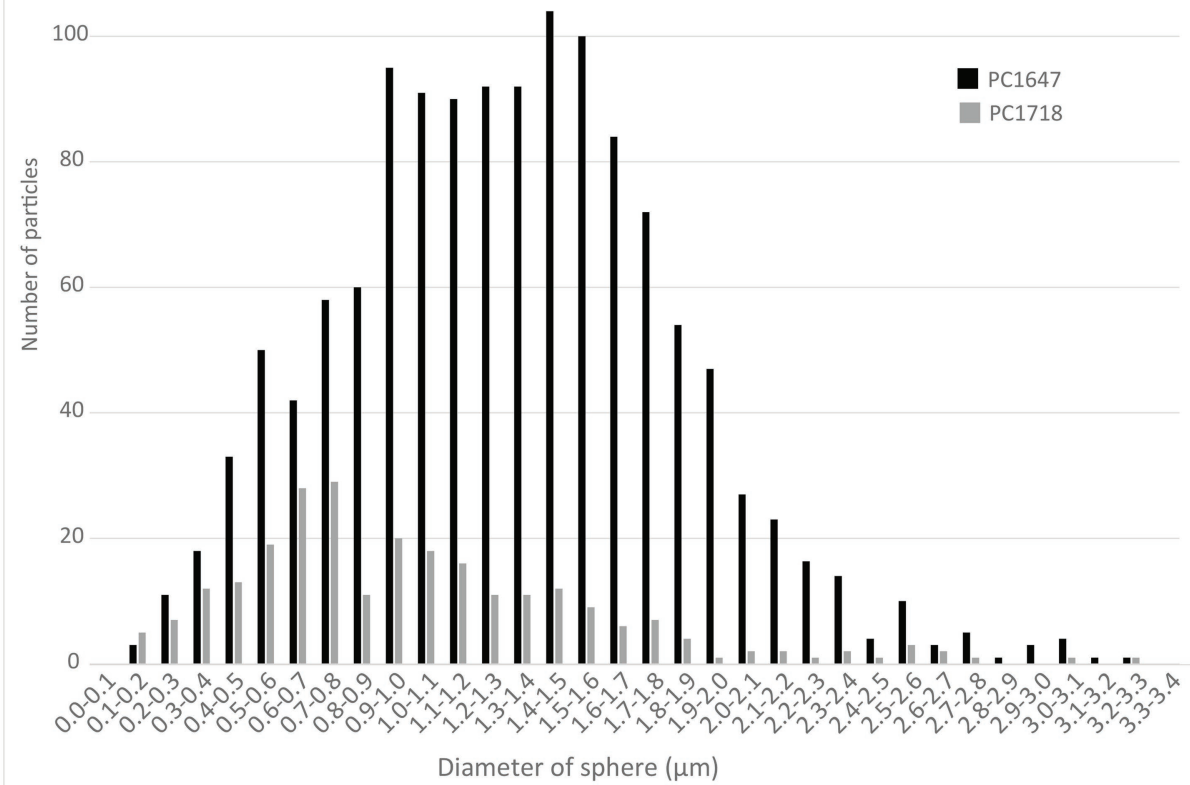

FIGURE 3 | Histograms depicting the size distributions of spherical S(0) particles in the PC1647 and PC1718 biofilm samples. 


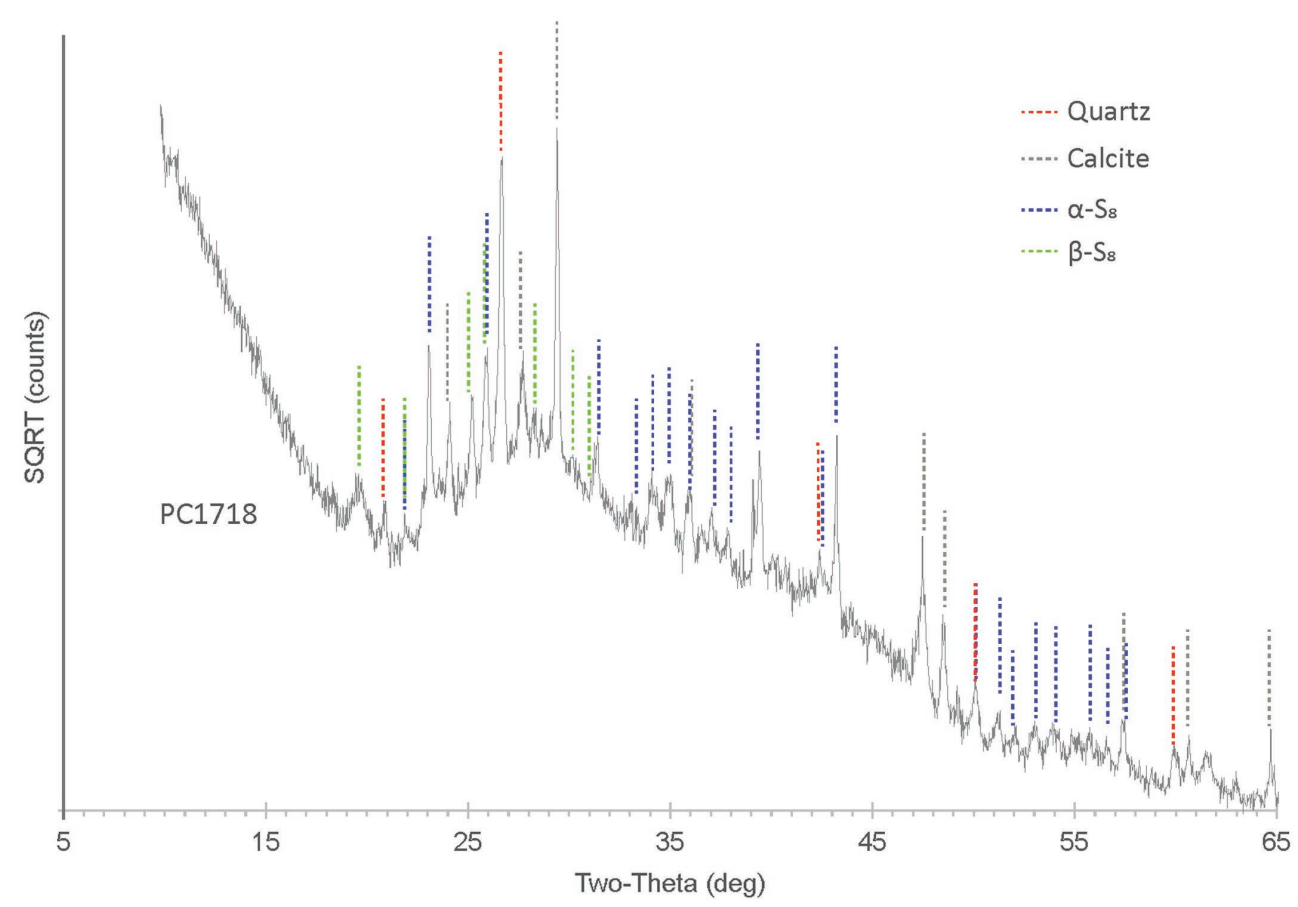

FIGURE 4 | XRD spectrum for biofilm sample PC1718. The peaks in the diffractogram include matches for $\alpha$ - $S_{8}, \beta-S_{8}$, quartz, and calcite.
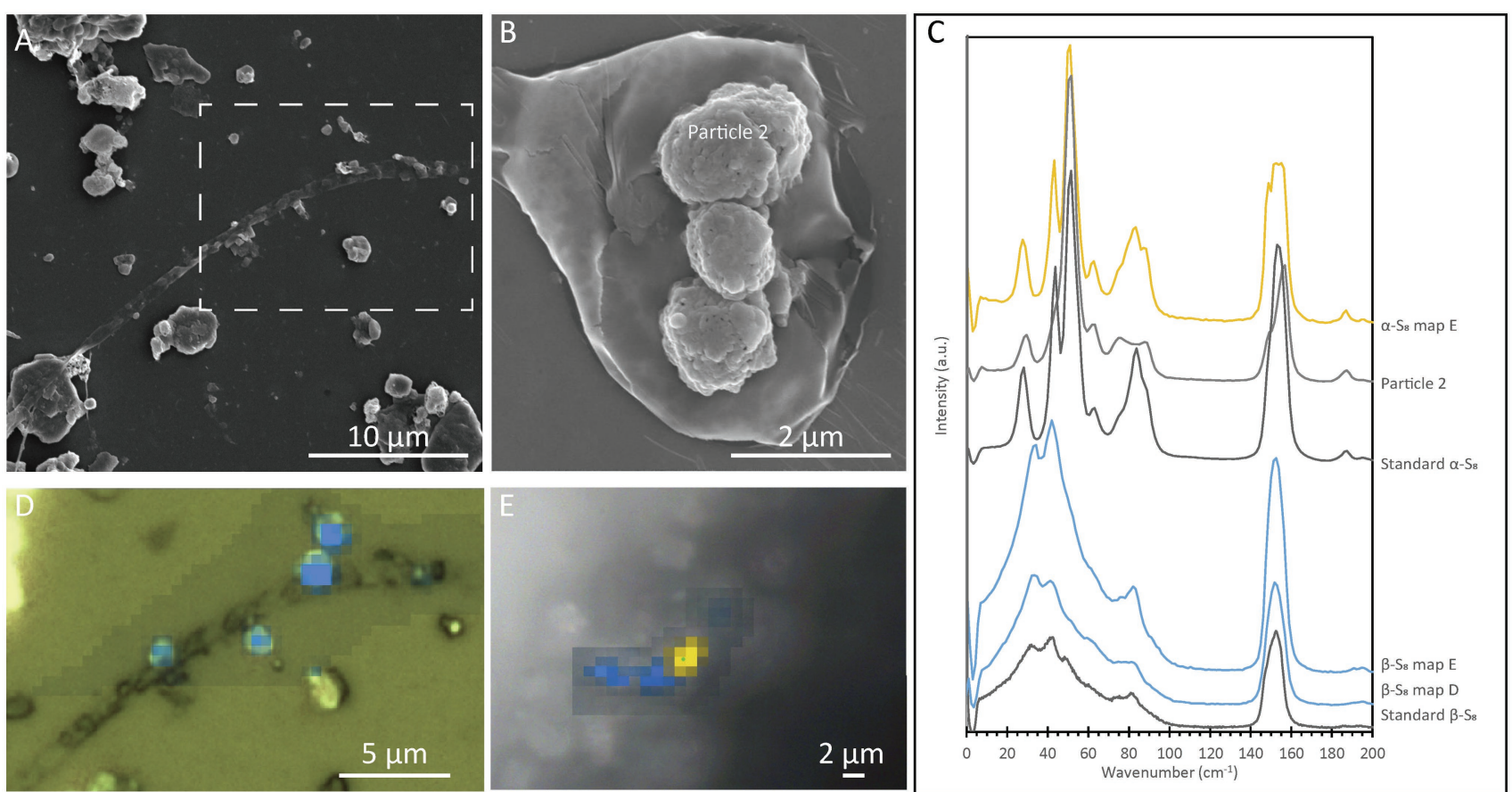

FIGURE 5 | Correlative SEM and Raman analyses of a filamentous cell with extracellular S(0) in the Sulfurovum-dominated streamer biofilm (sample PC1718). The sample was air-dried in images (A), (B), and (D), while Raman analyses (E) were performed while the sample was wet. (A) SEM image with a white dashed box indicating the location of the Raman map in (D); (B) SEM image of particles in sample PC1718. " $\alpha-S_{8}$ particle 2" indicates where the $\alpha-S_{8}$ Raman spectrum (labeled "Particle 2") in (C) was collected. (C) Ultra-low-frequency Raman spectra. Standard spectra for $\alpha$-S and $_{8}$-S S $_{8}$ are labeled accordingly. (D) Light microscopy image with an overlay Raman map. The blue areas are rich in $\beta-S_{8}$. (E) Light microscopy image with a Raman map overlaid. Yellow areas are rich in $\alpha-S_{8}$, and blue areas are rich in $\beta-S_{8}$. 


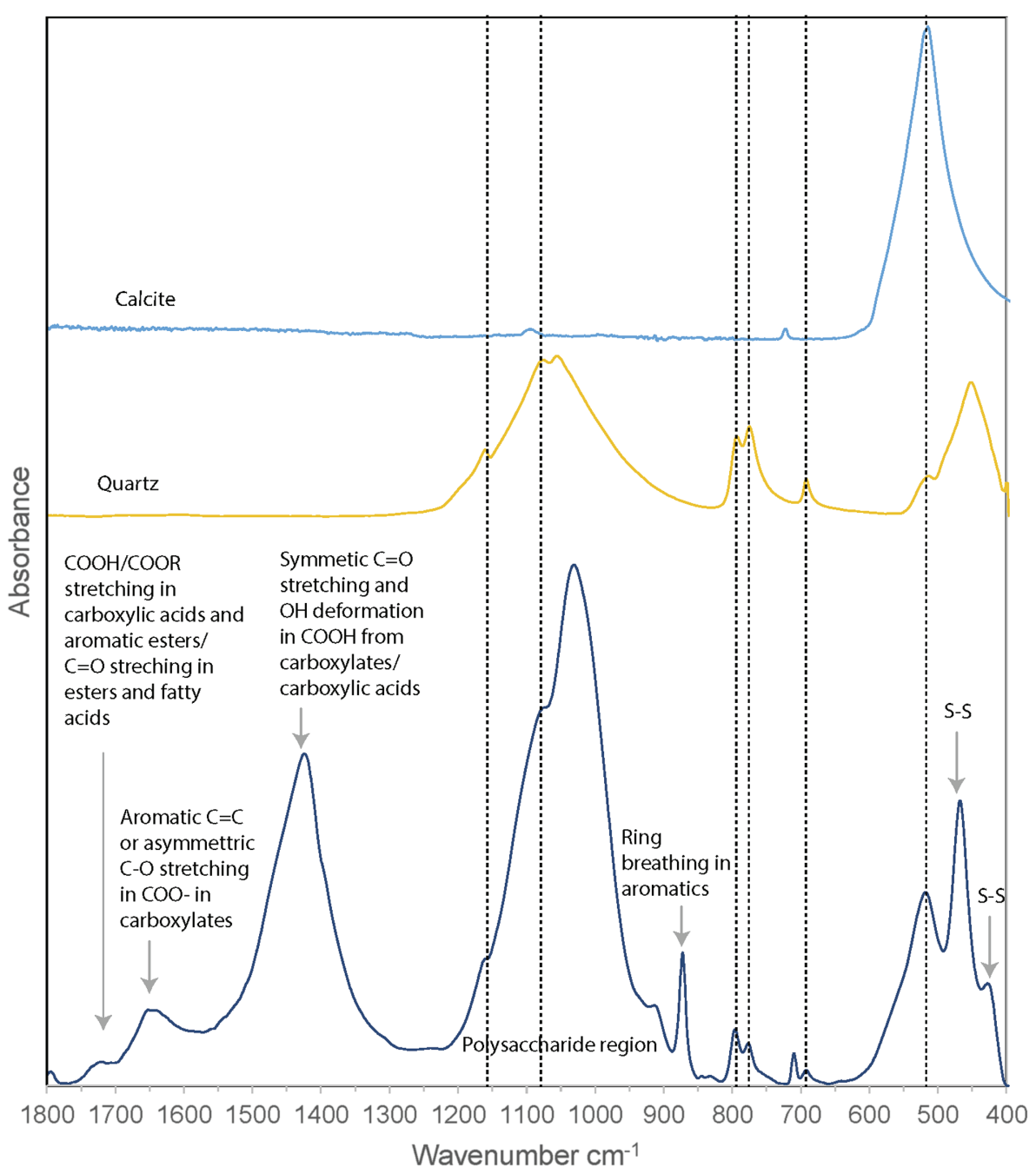

FIGURE 6 | FTIR spectrum of Sulfurovum-dominated streamer biofilm (sample PC1718), plotted with reference spectra for calcite and quartz. Dashed vertical lines indicate the positions of the peaks corresponding to calcite and quartz.

\section{Scanning Transmission X-Ray Microscopy at the C K-Edge and S L-Edge}

Scanning transmission X-ray microscopy analyses at the $\mathrm{S}$ L-edge of the Sulfurovum-dominated biofilms (samples PC1647 and PC1718) confirmed that $S(0)$ is the only form of particulate sulfur present in the samples (Supplementary Figure S4). C K-edge analyses showed the presence of bacteria along with two types of extracellular carbon materials: abundant EPS (as already observed in SEM images) and thin envelopes around $S(0)$ particles (Figure 7$)$. The thin organic envelopes are especially visible in STXM images and maps in places where $S(0)$ particles were vaporized due to the low pressure of the STXM chamber and X-ray beam damage (black arrows in Figure 7A).

All C K-edge XANES spectra display peaks at $285-285.2 \mathrm{eV}$, characteristic of $1 s \rightarrow \pi_{\mathrm{C}=\mathrm{C}}^{*}$ transitions in either aromatic or unsaturated carbon; Figure 8). The main peak in all spectra is located at $288.2 \mathrm{eV}$, corresponding to $1 \mathrm{~s} \rightarrow \pi^{*}$ transitions in amide groups of proteins (Benzerara et al., 2004; Haberstroh et al., 2006; Chan et al., 2011). The presence of amides is in contradiction with FTIR results which did not clearly detect this functional group. This discrepancy may be due to the fact that we focused our STXM analyses on clearly identifiable features, such as microbial cells and organic envelopes around $S(0)$ particles, while the signal from these small features may have been diluted by the signal of the more abundant EPS in bulk FTIR analyses. All spectra furthermore display a shoulder at $287.5 \mathrm{eV}$, corresponding to $3 s \rightarrow \sigma^{*}$ transitions in aliphatics (Haberstroh et al., 2006; Lehmann, 2009), and a small peak at $289.4 \mathrm{eV}$, corresponding to $1 \mathrm{~s} \rightarrow 3 \mathrm{p} / \sigma^{*}$ transitions in hydroxylic groups (Brandes et al., 2004). Some spectra (mostly EPS) have a peak at $288.5 \mathrm{eV}$, attributed to the $1 s \rightarrow \pi_{\mathrm{C}=\mathrm{O}}^{*}$ electronic transitions in carboxylics (Cody et al., 1998; Boyce et al., 2002; Chan et al., 2011). A small peak at $286.6 \mathrm{eV}$, representative of $1 \mathrm{~s} \rightarrow \pi^{\star}$ transitions in phenolic groups, ketones, carboxylates, 


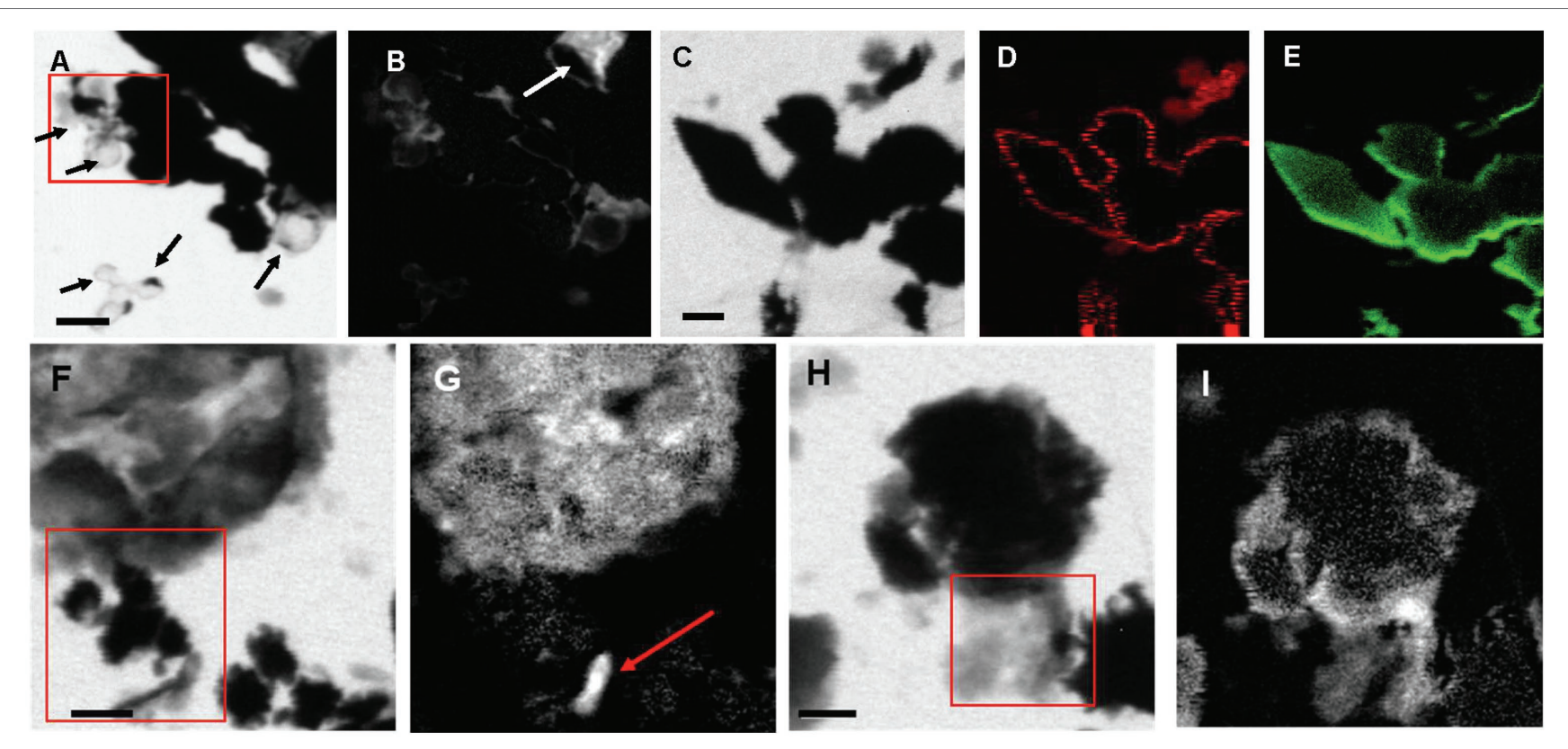

FIGURE 7 | STXM images and maps of Sulfurovum-dominated streamer biofilm. (A-B) Sample PC1647. (A) image collected at 288.1 eV. Black areas are S(0) particles. The empty spherical envelopes of vaporized S(0) globules are visible (black arrows). (B) Corresponding carbon map. The white arrow shows the carbon enveloped around a partially vaporized S(0) particle (a chain of S(O) bipyramids). (C-I) Sample PC1718. (C) Image collected at 288.2 eV. (D) Carbon map. (E) Sulfur map. (F) Image collected at $300 \mathrm{eV}$. (G) Carbon map. The arrow points to a rod-shaped microbial cell. (H-I) Image collected at 300 eV. (I) Carbon map. The boxes in $\mathbf{( A ) ,}(\mathbf{F})$, and $\mathbf{( H )}$ and the arrow in $\mathbf{( B )}$ indicate where XANES analyses shown in Figure $\mathbf{8}$ were performed. Scale bars: $1 \mu \mathrm{m}$.

or aldehydes (Myneni, 2002; Lehmann, 2009; Moffet et al., 2011; Cosmidis et al., 2019), is only present in the organic envelope of a $\mathrm{S}(0)$ chain (Figures 7B, 8). Spectra of EPS and $\mathrm{S}(0)$ envelopes sometimes display a shoulder at $288.7 \mathrm{eV}$, interpreted as $\mathrm{C} 1 s \rightarrow \pi_{\mathrm{C}=\mathrm{O}}^{*}$ electronic signature of acidic polysaccharides (Toner et al., 2009; Chan et al., 2011).

\section{DISCUSSION}

\section{Properties of the Biofilm S(0) Particles}

We described $S(0)$ particles forming within biofilms present in microaerophilic, sulfide-rich subsurface stream. The biofilms are dominated by Campylobacterota most closely related to Sulfurovum species (Jones et al., 2008; Macalady et al., 2008; Hamilton et al,, 2015), which are known to oxidize sulfide and thiosulfate to sulfate and/or extracellular S(0) (e.g., Campbell et al., 2006). Microbial sulfide oxidation rates are typically several orders of magnitude higher than chemical oxidation by molecular oxygen (Luther et al., 2011) suggesting that $S(0)$ particles in the Frasassi biofilms are primarily the product of microbial S-oxidation. However, mineral nucleation and growth within biofilms are often influenced by surrounding EPS, which may result in particle shapes, sizes, or crystal structures that differ from those of inorganically precipitated minerals (Tourney and Ngwenya, 2014). Here, we summarize our observations of the $S(0)$ particles in the Frasassi biofilms and suggest how formation within EPS may have influenced $S(0)$ properties. The results are also summarized in Figure 9.
The samples we examined contained both $S(0)$ spheroids and bipyramids, alongside more irregularly shaped particles (Figures 2, 7). Both spherical and bipyramidal morphologies have been observed in microbial biomineralization experiments, microbe-free organomineralization experiments, and inorganically precipitated $S(0)$. Extracellular $S(0)$ spheroids or globules are formed by diverse bacteria (Dahl and Prange, 2006; Marnocha et al., 2016; Cron et al., 2019). S(0) spheroids can also be formed through chemical precipitation of $\mathrm{S}(0)$ in the presence (Cosmidis et al., 2019) or in the absence (Marnocha et al., 2019) of organic compounds. Previous studies have suggested that bipyramids are typical of $S(0)$ precipitated in the absence of organics (Steudel, 2003). However, as noted above, bipyramids have also been observed in $S(0)$ organomineralization experiments with humic acids (Cosmidis et al., 2019) and in cultures of C. tepidum (Marnocha et al., 2019). The biofilm samples we examined contained $\mathrm{S}(0)$ spheroids ranging from 0.2 to $3.3 \mu \mathrm{m}$ (Figure 3) with median particle sizes near $1 \mu \mathrm{m}$. The PC1647 sample had larger $\mathrm{S}(0)$ spheroids. Larger particle size could be controlled by the age of the biofilm, or possibly by the growth of the biofilm on the twine support. Further analysis would be needed to confirm whether biofilm age and the nature of attachment surfaces influence particle size. S(0) particles with sizes ranging from $<0.2 \mu \mathrm{m}$ to $10 \mu \mathrm{m}$ have been observed in other natural environments (Findlay et al., 2014; Lau et al., 2017), in microbial cultures (Cron et al., 2019; Marnocha et al., 2019), in inorganically precipitated S(0) (Meyer, 1976; Garcia and Druschel, 2014), and in S(0) 


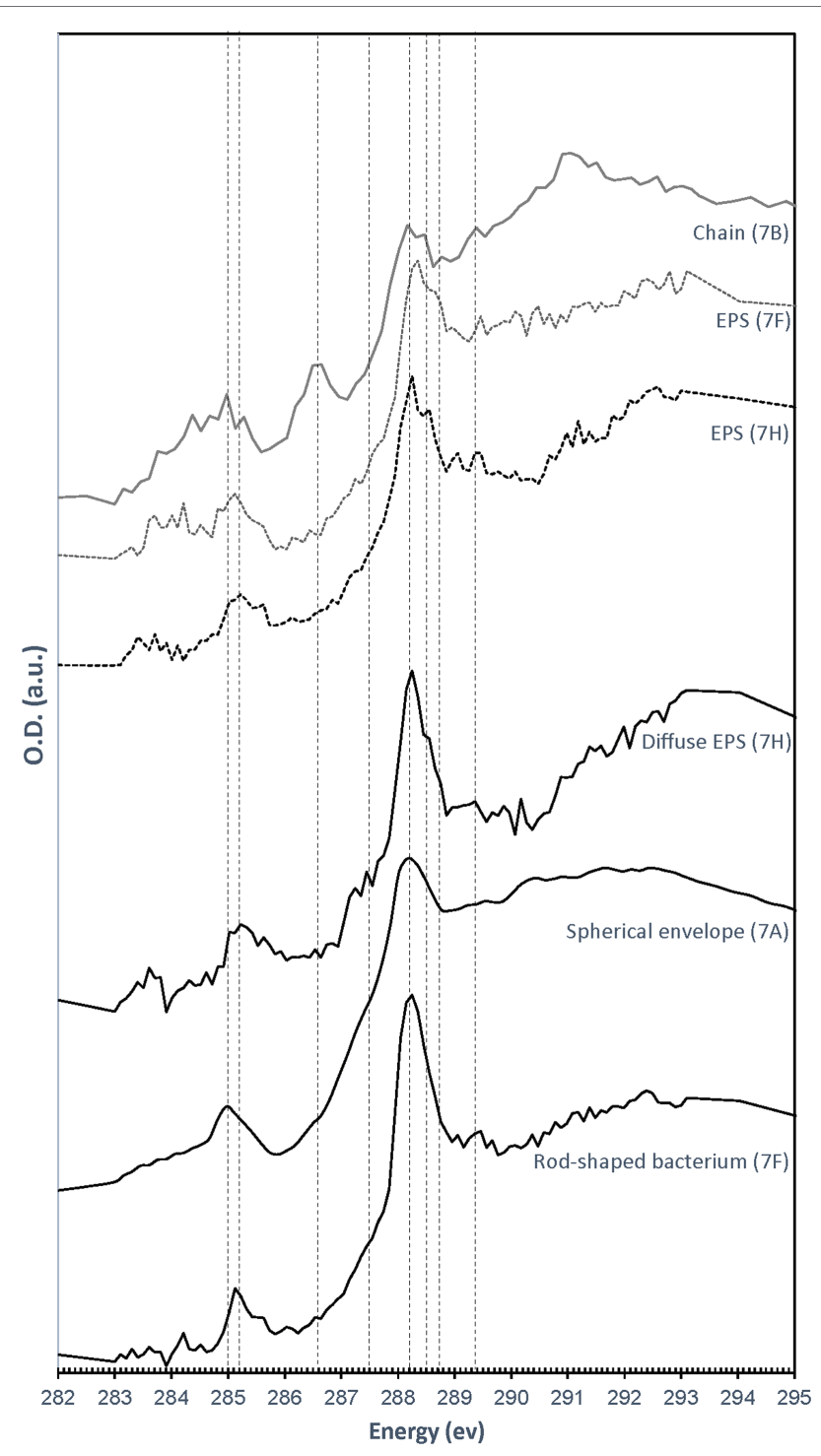

FIGURE 8 | C K-edge XANES spectra obtained on the particles and cells shown in Figure 7. Dashed lines correspond to absorption energies for different organic functional groups: $285 \mathrm{eV}$ ( $1 s \rightarrow \pi_{\mathrm{C}_{*}}^{*} \mathrm{C}$ transitions in aromatics or unsaturated carbon), $285.2 \mathrm{eV}$ ( $1 s \rightarrow \pi_{\mathrm{*}}^{*}=\mathrm{C}$ transitions in aromatics), $286.6 \mathrm{eV}$ ( $1 \mathrm{~s} \rightarrow \pi^{*}$ transitions in ketones, pyridines, and phenols), $287.5 \mathrm{eV}\left(3 \mathrm{~s} \rightarrow \sigma^{\star}\right.$ transitions in aliphatics), $288.2 \mathrm{eV}\left(1 \mathrm{~s} \rightarrow \pi^{\star}\right.$ transitions in amides), $288.5 \mathrm{eV}$ ( $1 s \rightarrow \pi_{\mathrm{C}=\mathrm{O}}^{*}$ transitions in carboxylic acids), $288.7 \mathrm{eV}$ ( $1 s \rightarrow \pi_{\mathrm{C}=\mathrm{O}}^{*}$ transitions in carboxyls in acidic polysaccharides), and $289.4 \mathrm{eV}$ $\left(1 \mathrm{~s} \rightarrow 3 \mathrm{p} / \sigma^{\star}\right.$ transitions in alcohols, ethers, and hydroxylated aliphatic compounds).

organomineralization experiments (Cosmidis et al., 2019). Particle sizes or morphologies of the S(0) described here are thus not particularly characteristic of their formation within microbial biofilms.

On the other hand, we observed both $\alpha-S_{8}$ and $\beta-S_{8} S(0)$ crystal structures in biofilm sample PC1718 (Figures 4, 5). The monoclinic sulfur allotrope $\beta-S_{8}$ is thermodynamically unstable at temperatures lower than $96^{\circ} \mathrm{C}$, as opposed to orthorhombic $\alpha-S_{8}$ which is the stable structure at room temperature (Steudel, 2003). In laboratory studies, metastable monoclinic $S(0)$ phases were formed abiotically at low temperature in the presence of organics (Guo et al., 2006; Choudhury et al., 2013; Moon et al., 2013; Cosmidis et al., 2019). In microbial incubations, soluble organic compounds produced by $S$. kujiense were found to play an important role in the formation and stabilization of extracellular $\beta-S_{8}$ particles in cultures and in spent media containing soluble organics (Cron et al., 2019). $\beta-S_{8}$ was also previously described from a low-temperature natural environment, and it was proposed that it was stabilized by its intimate association with organic matter (Lau et al., 2017).

Based on FTIR and XANES, the organic material associated with $S(0)$ in the biofilms has a complex composition dominated by carboxylic acids, amides, aromatics, and aliphatic compounds (Figures 6, 8). EPS is typically composed of DNA, polysaccharides, and lipids (Devaraj et al., 2019). These would include polyaromatic compounds and carboxylic substitutes (Flemming and Wingender, 2010). It is important to note that the organic compounds we observed are not merely "associated," but directly encapsulating $\mathrm{S}(0)$ particles (Figures 7A,B). Consistent with this observation, previous work describing organics associated with $\mathrm{S}(0)$ formed in organomineralization experiments demonstrated the presence of carboxylic (Cosmidis et al., 2019) and amide groups (Cosmidis and Templeton, 2016) in organic envelopes closely encapsulating $S(0)$ minerals. Pure cultures of the Sulfurovum relative $S$. kujiense also produced an amide-rich envelope around extracellular S(0) globules (Cron et al., 2019). Similarly, extracellular $S(0)$ produced by $C$. tepidum was encapsulated in organic envelopes composed of proteins and polysaccharides (Marnocha et al., 2019).

Both organic envelopes around $S(0)$ particles and the presence of the metastable allotrope $\beta-S_{8}$ thus confirm an important role for organic-mineral interactions in extracellular $\mathrm{S}(0)$ mineralization. We therefore hypothesize that microbially derived extracellular organics (EPS) are critical for the formation and preservation of $\mathrm{S}(0)$ particles in the Sulfurovumdominated biofilms at Frasassi, raising the interesting question below.

\section{$S(0)$ Organomineralization and Storage in Biofilms: A New Role for EPS?}

Extracellular formation of biominerals in close interaction with organic polymeric structures has been documented for different types of systems, for instance precipitation of calcium carbonates in microbial mats (Dupraz et al., 2009) or on diatom EPS (Stanton et al., 2021), or iron-(oxyhydr)oxide mineralization on polymeric bacterial sheaths and stalks (Chan et al., 2009, 2011). While in some cases mineral precipitation on extracellular organics may be "unintended and uncontrolled" (Frankel and Bazylinski, 2003), in other cases specific organic structures are involved in directing extracellular biomineralization and this process plays a crucial role in metabolism, growth, and/or survival (Miot et al., 2009; Chan et al., 2016). 


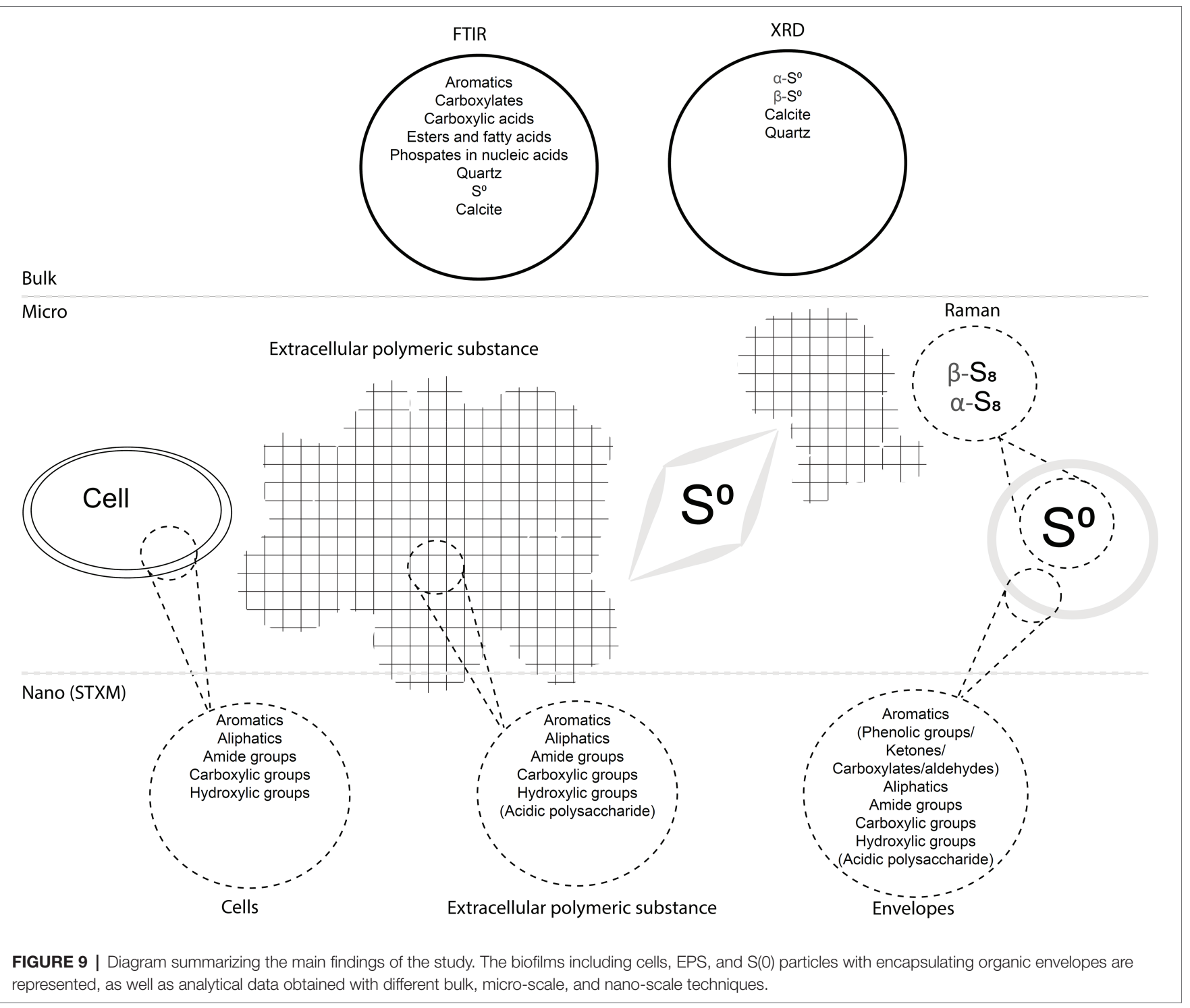

In the Frasassi Sulfurovum-rich biofilms, EPS appears to influence $\mathrm{S}(0)$ formed as a result of microbial S-oxidation, through the stabilization of otherwise unstable mineral phases. Organics have been shown to favor the formation and stabilization of $\mathrm{S}(0)$ minerals through $\mathrm{S}(0)$ organomineralization (Cosmidis and Templeton, 2016; Cosmidis et al., 2019). S(0) organomineralization may occur with diverse types of organic molecules (e.g., aminoacids, sugars, and humic acids; Cosmidis et al., 2019), as well as with soluble organic compounds produced by different types of bacteria (Cron et al., 2019). It remains to be determined whether specific organics are produced by the Frasassi biofilm microbial community to direct $S(0)$ formation and stabilization. Given that organic matter is energetically costly to produce (Amend et al., 2013; Jayathilake et al., 2017), particularly for autotrophs like Sulfurovum (LaRowe and Amend, 2015, 2016), we consider it unlikely that $S(0)$ encapsulation and particle trapping in the biofilm is accidental. Holdfasts in colonizing Sulfurovum populations appear to be made of $S(0)$ rather than organic matter, eliminating a potential role for EPS in biofilm attachment. These observations suggest that binding and encapsulating $\mathrm{S}(0)$ in EPS may represent a particular ecological strategy.

We can speculate about the ecological role that EPS and embedded $S(0)$ particles might play in the survival and dispersal of Sulfurovum populations in the cave habitat. In this environment, Sulfurovum-rich biofilms form only in turbulent stream flow near the air-water interface and are absent when appropriate support structures are unavailable in that position. The entrenched cave streams hosting the biofilms are subject to rapid, weather-related changes in water levels that frequently wash out or drown the biofilms. Thus cells that are producing $\mathrm{S}(0)$ under ideal conditions (Reaction 2) may experience rapid changes in $\mathrm{O}_{2}$ availability. Under $\mathrm{O}_{2}$ starvation conditions, bioavailable $\mathrm{S}(0)$ in the biofilm could enable survival and possibly even growth. 
Hamilton et al. (2015) noted that Sulfurovum metagenomeassembled genomes (MAGs) obtained from biofilms collected at the same sampling site ubiquitously contained genes that would allow $\mathrm{H}_{2}$ and formate oxidation with $\mathrm{S}(0)$ as an electron acceptor (Reaction 1).

$$
\begin{gathered}
\text { Reaction 1: } \mathrm{H}_{2}+\mathrm{S}^{0} \rightarrow \mathrm{H}_{2} \mathrm{~S} \quad \Delta G^{\circ \prime} \sim-30 \mathrm{~kJ} / \text { reaction } \\
\text { Reaction 2: } \mathrm{H}_{2} \mathrm{~S}+0.5 \mathrm{O}_{2} \rightarrow \mathrm{S}^{0}+\mathrm{H}_{2} \mathrm{O} \\
\Delta G^{\circ \prime}=-421 \mathrm{~kJ} / \text { reaction }
\end{gathered}
$$

Although Reaction 1 yields much less energy than Reaction 2 under standard conditions (and likely also under in situ conditions), the ability to utilize stored $S(0)$ may represent an important ecological advantage to the cave Sulfurovum populations, and capturing and storing $\mathrm{S}(0)$ in EPS may be an important element in the life strategy of this group. This scenario will be tested using metatranscriptomics in the future work. If so, energy storage through stabilization of electron donors for energy metabolism may be a previously underappreciated role for EPS in biofilms.

Extracellular polymeric substances in the Frasassi biofilms described here appear to be responsible for at least two properties of the $S(0)$ minerals: their crystal structure (with the stabilization of $\beta-S_{8}$ ) and organic encapsulation. It is now well established that the properties of $S(0)$ particles play a crucial role in their utilization by bacteria. For instance, particle size, surface area, and $\mathrm{S}^{0}$ composition and structure affect $\mathrm{S}(0)$ oxidation rates by Thiobacillus albertis (Laishley et al., 1986). Allochromatium vinosum grown on $\mathrm{S}(0)$ show a preference for polymeric sulfur over commercial crystalline $\mathrm{S}_{8}$, which they are unable to uptake (Franz et al., 2007). Preference for polymeric sulfur utilization over $\mathrm{S}_{8}$ was also evidenced in natural mats of chemotrophic S-oxidizers (Engel et al., 2007). Incubation experiments of natural freshwater communities with different sulfur sources showed a preference for the utilization of a reactive form of colloidal $S(0)$ possibly polythionates - over $\mathrm{S}_{8}$ (Findlay and Kamyshny, 2017). Recently, it was shown that C. tepidum can grow from the oxidation of its own biogenic $S(0)$ globules but not from oxidation of commercial sulfur, crystalline $S(0)$, or inorganically precipitated colloidal $S(0)$, which is mineralogically very similar to biogenic $S(0)$ globules but does not have an organic coating (Marnocha et al., 2016, 2019). It is possible that $S(0)$ formation within EPS favors storage in a form more readily utilizable by the cells, by favoring metastable $S(0)$ structures and by making $S(0)$ particles hydrophilic, allowing interaction with the cell surface (Marnocha et al., 2019).

\section{CONCLUSION}

We studied a natural Sulfurovum-rich S(0)-producing biofilm to investigate processes that influence the precipitation and stabilization of extracellular $S(0)$ in the environment. We found that sulfur particles in the biofilm are encapsulated within organic envelopes and that some of the particles have an unstable crystal structure (the high-temperature allotrope $\beta-S_{8}$ ). These characteristics have also been observed in $S(0)$ produced by organomineralization. Our results suggest that EPS within the biofilm stabilize $S(0)$ particles, preventing their dispersal away from the biofilm and influencing their structural and surface properties. Future studies will be needed in order to determine the ecological importance of this process and its impact on biogeochemical sulfur cycling in the Frasassi cave and in other environments.

\section{DATA AVAILABILITY STATEMENT}

The original contributions presented in the study are included in the article/Supplementary Material, and further inquiries can be directed to the corresponding author.

\section{AUTHOR CONTRIBUTIONS}

BC, JM, and JC designed the study. BC and JM collected the samples. BC and JC performed the analyses. All authors participated in data interpretation. BC wrote the manuscript with input from JC and JM. All authors contributed to the article and approved the submitted version.

\section{FUNDING}

Support for this study was provided by the Penn State Department of Geosciences through startup funding to JC. BC was supported by the Penn State Department of Geosciences Distinguished Postdoctoral Fellowship. Sample collection and fieldwork were funded by an NSF grant to JM (EAR1252128).

\section{ACKNOWLEDGMENTS}

We thank C. Nims and M. Wetherington (Penn State University) for help with Raman analyses and T. J. Zimudzi (Penn State University) for help with FTIR measurements. The use of the SSRL, SLAC National Accelerator Laboratory, is supported by the US Department of Energy, Office of Science, Office of Basic Energy Sciences under Contract No. DE-AC02-76SF00515. We thank J. Wang for providing support on STXM beamline SM of the Canadian Light Source (CLS, Saskatoon, Canada). CLS is supported by the Canada Foundation for Innovation, Natural Sciences and Engineering Research Council of Canada, the University of Saskatchewan, the Government of Saskatchewan, Western Economic Diversification Canada, the National Research Council Canada, and the Canadian Institutes of Health Research. The authors are grateful to A. Montanari for providing facilities and laboratory space at the Osservatorio Geologico di Coldigioco in Apiro, Italy. Fieldwork was carried out in collaboration with C. Chan, C. Clark, and P. Henri with assistance from 
M. Mainiero, S. Mariani, and S. Recanatini. Melissa Peacock (Salish Sea Research Center) is thanked for providing funding to $\mathrm{BC}$ for publication fees through the National Science Foundation Tribal Colleges and Universities Program Award No. 1840199.

\section{REFERENCES}

Amend, J. P., LaRowe, D. E., McCollom, T. M., and Shock, E. L. (2013). The energetics of organic synthesis inside and outside the cell. Philos. Trans. Royal Soc. B Biol. Sci. 368:20120255. doi: 10.1098/rstb.2012.0255

Artz, R., Chapman, S., Robertson, J., Potts, J., Laggoun-Défarge, F., Gogo, S., et al. (2008). FTIR spectroscopy can be used as a screening tool for organic matter quality in regenerating cutover peatlands. Soil Biol. Biochem. 40, 515-527. doi: 10.1016/j.soilbio.2007.09.019

Benzerara, K., Yoon, T. H., Tyliszczak, T., Constantz, B., Spormann, A., and Brown, G. E. Jr. (2004). Scanning transmission X-ray microscopy study of microbial calcification. Geobiology 2, 249-259. doi: 10.1111/j.1472-4677. 2004.00039.x

Boyce, C. K., Cody, G. D., Feser, M., Jacobsen, C., Knoll, A. H., and Wirick, S. (2002). Organic chemical differentiation within fossil plant cell walls detected with X-ray spectromicroscopy. Geology 30, 1039-1042. doi: 10.1130/00917613(2002)030<1039:OCDWFP>2.0.CO;2

Brandes, J. A., Lee, C., Wakeham, S., Peterson, M., Jacobsen, C., Wirick, S., et al. (2004). Examining marine particulate organic matter at sub-micron scales using scanning transmission X-ray microscopy and carbon X-ray absorption near edge structure spectroscopy. Mar. Chem. 92, 107-121. doi: 10.1016/j.marchem.2004.06.020

Brune, D. C. (1995). Isolation and characterization of sulfur globule proteins from Chromatium vinosum and Thiocapsa roseopersicina. Arch. Microbiol. 163, 391-399. doi: 10.1007/BF00272127

Campbell, B. J., Engel, A. S., Porter, M. L., and Takai, K. (2006). The versatile epsilon-proteobacteria: key players in sulphidic habitats. Nat. Rev. Microbiol. 4, 458-468. doi: 10.1038/nrmicro1414

Chan, C. S., Fakra, S. C., Edwards, D. C., Emerson, D., and Banfield, J. F. (2009). Iron oxyhydroxide mineralization on microbial extracellular polysaccharides. Geochim. Cosmochim. Acta 73, 3807-3818. doi: 10.1016/j. gca.2009.02.036

Chan, C. S., Fakra, S. C., Emerson, D., Fleming, E. J., and Edwards, K. J. (2011). Lithotrophic iron-oxidizing bacteria produce organic stalks to control mineral growth: implications for biosignature formation. ISME J. 5, 717-727. doi: $10.1038 /$ ismej.2010.173

Chan, C. S., McAllister, S. M., Leavitt, A. H., Glazer, B. T., Krepski, S. T., and Emerson, D. (2016). The architecture of iron microbial mats reflects the adaptation of chemolithotrophic iron oxidation in freshwater and marine environments. Front. Microbiol. 7:796. doi: 10.3389/fmicb.2016.00796

Choudhury, S., Mandal, A., Chakravorty, D., Gopal, M., and Goswami, A. (2013). Evaluation of physicochemical properties, and antimicrobial efficacy of monoclinic sulfur-nanocolloid. J. Nanopart. Res. 15:1491. doi: 10.1007/ s11051-013-1491-y

Cody, G. D., Ade, H., Wirick, S., Mitchell, G. D., and Davis, A. (1998). Determination of chemical-structural changes in vitrinite accompanying luminescence alteration using C-NEXAFS analysis. Org. Geochem. 28, 441-455. doi: 10.1016/S0146-6380(98)00010-2

Cosmidis, J., and Benzerara, K. (2014). Soft X-ray Scanning Transmission SpectroMicroscopy. Boca Raton: CRC Press.

Cosmidis, J., Nims, C. W., Diercks, D., and Templeton, A. S. (2019). Formation and stabilization of elemental sulfur through organomineralization. Geochim. Cosmochim. Acta 247, 59-82. doi: 10.1016/j.gca.2018.12.025

Cosmidis, J., and Templeton, A. S. (2016). Self-assembly of biomorphic carbon/ sulfur microstructures in sulfidic environments. Nat. Commun. 7:12812. doi: $10.1038 /$ ncomms 12812

Cron, B., Henri, P., Chan, C. S., Macalady, J. L., and Cosmidis, J. (2019). Elemental Sulfur formation by Sulfuricurvum kujiense is mediated by extracellular organic compounds. Front. Microbiol. 10:2710. doi: 10.3389/ fmicb. 2019.02710

\section{SUPPLEMENTARY MATERIAL}

The Supplementary Material for this article can be found online at: https://www.frontiersin.org/articles/10.3389/fmicb.2021.720101/ full\#supplementary-material

D’Angeli, I. M., Parise, M., Vattano, M., Madonia, G., Galdenzi, S., and De Waele, J. (2019). Sulfuric acid caves of Italy: A review. Geomorphology 333, 105-122. doi: 10.1016/j.geomorph.2019.02.025

Dahl, C. (2020a). "Bacterial intracellular sulphur globules," in Bacterial Organelles and Organelle-like Inclusions. ed. D. Jendrossek (Cham: Springer International Publishing), 19-51.

Dahl, C. (2020b). "A biochemical view on the biological sulfur cycle," in Environmental Technologies to Treat Sulfur Pollution: Principles and Engineering. ed. P. N. L. Lens (London, UK: IWA Publishing), 55-96.

Dahl, C., and Prange, A. (2006). "Bacterial sulfur globules: occurrence, structure and metabolism," in Inclusions in Prokaryotes. ed. J. M. Shively (Berlin: Springer), 21-51

Devaraj, A., Buzzo, J. R., Mashburn-Warren, L., Gloag, E. S., Novotny, L. A. Stoodley, P., et al. (2019). The extracellular DNA lattice of bacterial biofilms is structurally related to Holliday junction recombination intermediates. Proc. Natl. Acad. Sci. 116, 25068-25077. doi: 10.1073/pnas.1909017116

Dupraz, C., Reid, R. P., Braissant, O., Decho, A. W., Norman, R. S., and Visscher, P. T. (2009). Processes of carbonate precipitation in modern microbial mats. Earth Sci. Rev. 96, 141-162. doi: 10.1016/j.earscirev. 2008.10.005

Engel, A. S., Lichtenberg, H., Prange, A., and Hormes, J. (2007). Speciation of sulfur from filamentous microbial mats from sulfidic cave springs using X-ray absorption near-edge spectroscopy. FEMS Microbiol. Lett. 269, 54-62. doi: $10.1111 /$ j.1574-6968.2006.00600.x

Findlay, A. J., Gartman, A., MacDonald, D. J., Hanson, T. E., Shaw, T. J., and Luther, G. W. (2014). Distribution and size fractionation of elemental sulfur in aqueous environments: The Chesapeake Bay and Mid-Atlantic Ridge. Geochim. Cosmochim. Acta 142, 334-348. doi: 10.1016/j.gca.2014. 07.032

Findlay, A. J., and Kamyshny, A. (2017). Turnover rates of intermediate sulfur species (Sx2-, S0, S2O32-, S4O62-, SO32-). in anoxic freshwater and sediments. Front. Microbiol. 8:2551. doi: 10.3389/fmicb.2017.02551

Flemming, H.-C., and Wingender, J. (2010). The biofilm matrix. Nat. Rev. Microbiol. 8, 623-633. doi: 10.1038/nrmicro2415

Frankel, R. B., and Bazylinski, D. A. (2003). Biologically induced mineralization by bacteria. Rev. Mineral. Geochem. 54, 95-114. doi: 10.2113/0540095

Franz, B., Lichtenberg, H., Hormes, J., Modrow, H., Dahl, C., and Prange, A. (2007). Utilization of solid "elemental" sulfur by the phototrophic purple sulfur bacterium Allochromatium vinosum: a sulfur K-edge X-ray absorption spectroscopy study. Microbiology 153, 1268-1274. doi: 10.1099/mic.0. 2006/003954-0

Garcia, A. A. Jr., and Druschel, G. K. (2014). Elemental sulfur coarsening kinetics. Geochem. Trans. 15:11. doi: 10.1186/s12932-014-0011-z

Gray, N. D., and Head, I. M. (1999). New insights on old bacteria: diversity and function of morphologically conspicuous sulfur bacteria in aquatic systems. Hydrobiologia 401, 97-112. doi: 10.1023/A:1003794529171

Gregersen, L., Bryant, D., and Frigaard, N.-U. (2011). Mechanisms and evolution of oxidative sulfur metabolism in green sulfur bacteria. Front. Microbiol. 2:00116. doi: 10.3389/fmicb.2011.00116

Guo, Y., Zhao, J., Yang, S., Yu, K., Wang, Z., and Zhang, H. (2006). Preparation and characterization of monoclinic sulfur nanoparticles by water-in-oil microemulsions technique. Powder Technol. 162, 83-86. doi: 10.1016/j. powtec.2005.12.012

Haberstroh, P. R., Brandes, J. A., Gélinas, Y., Dickens, A. F., Wirick, S., and Cody, G. (2006). Chemical composition of the graphitic black carbon fraction in riverine and marine sediments at sub-micron scales using carbon X-ray spectromicroscopy. Geochim. Cosmochim. Acta 70, 1483-1494. doi: 10.1016/j. gca.2005.12.001

Hamilton, T. L., Jones, D. S., Schaperdoth, I., and Macalady, J. L. (2015). Metagenomic insights into $\mathrm{S}(0)$ precipitation in a terrestrial subsurface 
lithoautotrophic ecosystem. Front. Microbiol. 5:00756. doi: 10.3389/ fmicb.2014.00756

Hansen, T. A., and van Gemerden, H. (1972). Sulfide utilization by purple nonsulfur bacteria. Arch. Mikrobiol. 86, 49-56. doi: 10.1007/ BF00412399

Hanson, T. E., Bonsu, E., Tuerk, A., Marnocha, C. L., Powell, D. H., and Chan, C. S. (2016). Chlorobaculum tepidum growth on biogenic $S(0)$ as the sole photosynthetic electron donor. Environ. Microbiol. 18, 2856-2867. doi: $10.1111 / 1462-2920.12995$

Jayathilake, P. G., Jana, S., Rushton, S., Swailes, D., Bridgens, B., Curtis, T., et al. (2017). Extracellular polymeric substance production and aggregated bacteria colonization influence the competition of microbes in biofilms. Front. Microbiol. 8:1865. doi: 10.3389/fmicb.2017.01865

Jones, D., Lyon, E., and Macalady, J. (2008). Geomicrobiology of biovermiculations from the Frasassi Cave System, Italy. J. Cave Karst 70, 78-93.

Jørgensen, B. B., Findlay, A. J., and Pellerin, A. (2019). The biogeochemical sulfur cycle of marine sediments. Front. Microbiol. 10:00849. doi: 10.3389/ fmicb.2019.00849

Kleinjan, W. E., de Keizer, A., and Janssen, A. J. H. (2003). Biologically Produced Sulfur, Elemental Sulfur and Sulfur-Rich Compounds I. Topics in Current Chemistry. Berlin, Heidelberg: Springer, 167-188.

Kleinjan, W. E., de Keizer, A., and Janssen, A. J. H. (2005). Equilibrium of the reaction between dissolved sodium sulfide and biologically produced sulfur. Colloids Surf. B: Biointerfaces 43, 228-237. doi: 10.1016/j. colsurfb.2005.05.004

Lafuente, B., Downs, R. T., Yang, H., and Stone, N. (2015). "The power of databases: the RRUFF project," in Highlights in Mineralogical Crystallography. eds. T. Armbruster and R. M. Danisi (Berlin, München, Boston: De Gruyter) $1-30$.

Laishley, E. J., Bryant, R. D., Kobryn, B. W., and Hyne, J. B. (1986). Microcrystalline structure and surface area of elemental sulphur as factors influencing its oxidation by Thiobacillus albertis. Can. J. Microbiol. 32, 237-242. doi: 10.1139/ m86-047

LaRowe, D. E., and Amend, J. P. (2015). Catabolic rates, population sizes and doubling/replacement times of microorganisms in natural settings. Am. J. Sci. 315, 167-203. doi: 10.2475/03.2015.01

LaRowe, D. E., and Amend, J. P. (2016). The energetics of anabolism in natural settings. ISME J. 10, 1285-1295. doi: 10.1038/ismej.2015.227

Lau, G. E., Cosmidis, J., Grasby, S. E., Trivedi, C. B., Spear, J. R., and Templeton, A. S. (2017). Low-temperature formation and stabilization of rare allotropes of cyclooctasulfur ( $\beta$-S 8 and $\gamma$-S 8 ) in the presence of organic carbon at a sulfur-rich glacial site in the Canadian High Arctic. Geochim. Cosmochim. Acta. 200, 218-231. doi: 10.1016/j.gca.2016. 11.036

Lehmann, J., Solomon, D., Brandes, J., Fleckenstein, H., Jacobson, C., and Thieme, J. (2009). "Synchrotron-based near-edge X-ray spectroscopy of natural organic matter in soils and sediments," in Biophysico-Chemical Processes Involving Natural Nonliving Organic Matter in Environmental Systems. eds. N. Senesi, B. Xing and P. M. Huang (Hoboken, NJ, USA: John Wiley \& Sons, Inc.), 729-781.

Luther, G. W., Findlay, A., MacDonald, D., Owings, S., Hanson, T., Beinart, R., et al. (2011). Thermodynamics and kinetics of sulfide oxidation by oxygen: a look at inorganically controlled reactions and biologically mediated processes in the environment. Front. Microbiol. 2:62. doi: 10.3389/fmicb. 2011.00062

Macalady, J. L., Dattagupta, S., Schaperdoth, I., Jones, D. S., Druschel, G. K., and Eastman, D. (2008). Niche differentiation among sulfur-oxidizing bacterial populations in cave waters. ISME J. 2, 590-601. doi: 10.1038/ ismej.2008.25

Maki, J. S. (2013). Bacterial intracellular sulfur globules: structure and function. Microbial Physiol. 23, 270-280. doi: 10.1159/000351335

Marnocha, C. L., Levy, A. T., Powell, D. H., Hanson, T. E., and Chan, C. S. (2016). Mechanisms of extracellular S0 globule production and degradation in Chlorobaculumtepidum via dynamic cell-globule interactions. Microbiology 162, 1125-1134. doi: 10.1099/mic.0.000294

Marnocha, C. L., Sabanayagam, C. R., Modla, S., Powell, D. H., Henri, P. A., Steele, A. S., et al. (2019). Insights into the mineralogy and surface chemistry of extracellular biogenic S0 globules produced by Chlorobaculum tepidum. Front. Microbiol. 10:271. doi: 10.3389/fmicb.2019.00271
Meyer, B. (1976). Elemental sulfur. Chem. Rev. 76, 367-388. doi: 10.1021/ cr60301a003

Miot, J., Benzerara, K., Obst, M., Kappler, A., Hegler, F., Schädler, S., et al. (2009). Extracellular iron biomineralization by photoautotrophic ironoxidizing bacteria. Appl. Environ. Microbiol. 75, 5586-5591. doi: 10.1128/ AEM.00490-09

Moffet, R., Tivanski, A., and Gilles, M. (2011). "Scanning transmission X-ray microscopy: applications in atmospheric aerosol research," Fundamentals and Applications in Aerosol Spectroscopy. eds. R. Signorell and J. Reid (Boca Raton, FL, USA: CRC Press), 419-462.

Moon, S., Jung, Y. H., Jung, W. K., Jung, D. S., Choi, J. W., and Kim, D. K. (2013). Encapsulated Monoclinic Sulfur for Stable Cycling of Li-S Rechargeable Batteries. Adv. Mater. 25, 6547-6553. doi: 10.1002/adma. 201303166

Myneni, S. C. B. (2002). Soft X-ray Spectroscopy and Spectromicroscopy Studies of Organic Molecules in the Environment. Rev. Mineral. Geochem. 49, 485-579. doi: $10.2138 /$ gsrmg.49.1.485

Naumann, D., Helm, D., and Labischinski, H. (1991). Microbiological characterizations by FT-IR spectroscopy. Nature 351, 81-82. doi: $10.1038 / 351081 \mathrm{a} 0$

Nims, C., Cron, B., Wetherington, M., Macalady, J., and Cosmidis, J. (2019). Low frequency Raman Spectroscopy for micron-scale and in vivo characterization of elemental sulfur in microbial samples. Sci. Rep. 9:7971. doi: 10.1038/s41598-019-44353-6

Oren, A., and Shilo, M. (1979). Anaerobic heterotrophic dark metabolism in the cyanobacterium Oscillatoria limnetica: Sulfur respiration and lactate fermentation. Arch. Microbiol. 122, 77-84. doi: 10.1007/BF00408049

Orhan Yanıkan, E., Gulseren, G., and Ayhan, K. (2020). Protein profile of bacterial extracellular polymeric substance by Fourier transform infrared spectroscopy. Microchem. J. 156:104831. doi: 10.1016/j.microc.2020.104831

Pasteris, J., J Freeman, J., Goffredi, S., and Buck, K. (2001). Raman spectroscopic and laser scanning confocal microscopic analysis of sulfur in living sulfurprecipitating marine bacteria. Chem. Geol. 180, 3-18. doi: 10.1016/S00092541(01)00302-3

Prange, A., Chauvistre, R., Modrow, H., Hormes, J., Truper, H. G., and Dahl, C. (2002). Quantitative speciation of sulfur in bacterial sulfur globules: X-ray absorption spectroscopy reveals at least three different species of sulfur. Microbiology 148, 267-276. doi: 10.1099/00221287-148-1-267

Rickard, D., and Luther, G. W. I. (2007). Chemistry of Iron Sulfides. Chem. Rev. 107, 514-562. doi: 10.1021/cr0503658

Schmitt, J., and Flemming, H. (1998). FTIR-spectroscopy in microbial and material analysis. Int. Biodeterior. Biodegradation 41, 1-11. doi: 10.1016/ S0964-8305(98)80002-4

Stanton, C., Cosmidis, J., and Kump, L. (2021). Are-examination of the mechanism of whiting events: a new role for diatoms in Fayetteville Green Lake (New York, USA). EarthArXiv, 2335.

Steudel, R. (2003). "Aqueous Sulfur Sols," in Elemental Sulfur and Sulfur-Rich Compounds I. ed. R. Steudel (Berlin, Heidelberg: Springer), 153-166.

Steudel, R., and Eckert, B. (2003). "Solid sulfur allotropes," in Elemental Sulfur and Sulfur-Rich Compounds I. ed. R. Steudel (Berlin, Heidelberg: Springer), $1-80$.

Then, J., and Trüper, H. G. (1983). Sulfide oxidation in Ectothiorhodospira abdelmalekii. Evidence for the catalytic role of cytochrome c-551. Arch. Microbiol. 135, 254-258. doi: 10.1007/BF00413477

Thomas, G. J. (1972). Applications of infrared spectroscopy in biochemistry, biology, and medicine. Frank S. Parker. Q. Rev. Biol. 47:477. doi: 10.1086/ 407481

Toner, B. M., Fakra, S. C., Manganini, S. J., Santelli, C. M., Marcus, M. A., Moffett, J. W., et al. (2009). Preservation of iron(II) by carbon-rich matrices in a hydrothermal plume. Nat. Geosci. 2, 197-201. doi: 10.1038/ngeo433

Tourney, J., and Ngwenya, B. T. (2014). The role of bacterial extracellular polymeric substances in geomicrobiology. Chem. Geol. 386, 115-132. doi: 10.1016/j.chemgeo.2014.08.011

Warthmann, R., Cypionka, H., and Pfennig, N. (1992). Photoproduction of $\mathrm{H} 2$ from acetate by syntrophic cocultures of green sulfur bacteria and sulfur-reducing bacteria. Arch. Microbiol. 157, 343-348. doi: 10.1007/ BF00248679

Zerkle, A., Kamyshny, A., Kump, L., Farquhar, J., Oduro, H., and Arthur, M. (2010). Sulfur cycling in a stratified euxinic lake with moderately high 
sulfate: constraints from quadruple S isotopes. Geochim. Cosmochim. Acta 17, 4953-4970. doi: 10.1016/j.gca.2010.06.015

Conflict of Interest: The authors declare that the research was conducted in the absence of any commercial or financial relationships that could be construed as a potential conflict of interest.

Publisher's Note: All claims expressed in this article are solely those of the authors and do not necessarily represent those of their affiliated organizations, or those of the publisher, the editors and the reviewers. Any product that may be evaluated in this article, or claim that may be made by its manufacturer, is not guaranteed or endorsed by the publisher.

Copyright (c) 2021 Cron, Macalady and Cosmidis. This is an open-access article distributed under the terms of the Creative Commons Attribution License (CC BY). The use, distribution or reproduction in other forums is permitted, provided the original author(s) and the copyright owner(s) are credited and that the original publication in this journal is cited, in accordance with accepted academic practice. No use, distribution or reproduction is permitted which does not comply with these terms. 